East African Medical Journal Vol $7 \dot{9}$ No. 6 June 2002

RISK AWARENESS, EXPOSURE TO ORAL HEALTH INFORMATION, ORAL HEALTH RELATED BELIEFS AND BEHAVIOURS AMONG STUDENTS ATTENDING HIGHER LEARNING INSTITUTIONS IN DAR ES SALAAM, TANZANIA

J. Masalu, Muhimbili Medical Centre, School of Assistant Dental Officers, Dar es Salaam, Tanzania; Centre for International Health. University of Bergen. Norway, M. Mtaya, Muhimbili Medical Centre. School of Assistant Dental Officers, Dar es Salaam, Tanzania and A.N. Åstrøm, Centre for International Health, University of Bergen; Department of Odontology-Community Dentistry, University of Bergen, Norway

Request for reprints to: A.N. Åstrøm, Centre for International Health, Armauer Hansen Building, N-5021, Bergen, Norway

\title{
RISK AWARENESS, EXPOSURE TO ORAL HEALTH INFORMATION, ORAL HEALTH RELATED BELIEFS AND BEHAVIOURS AMONG STUDENTS ATTENDING HIGHER LEARNING INSTITUTIONS IN DAR ES SALAAM, TANZANIA
}

\author{
J. MASALU, M. MTAYA and A.N. ÅSTRøM
}

\begin{abstract}
Objective: To assess the level of exposure to information about oral health from local sources, risk awareness, oral health beliefs and behaviours among male and female students attending higher learning institutions in Dar es Salaam.

Design: A cross sectional survey.

Setting: Government recognised higher education institutions in Dar es Salaam, Tanzania in 1999.

Subjects: The study population comprised of 1123 university students in Dar es Salaam. Main outcome measures: Level of risk awareness, exposure to oral health information, oral health beliefs and behaviour among students.

Results: Despite apparent misconceptions, the level of risk awareness was generally high and did not differ between male and female students. Univariate analysis of variance revealed that female students were exposed to more oral health information, had stronger oral beliefs and performed preventive behaviours more frequently than did their male counterparts. In multiple linear regression analysis, beliefs about the importance of preventive behaviours were significantly related to the frequency with which such habits occurred $(\beta=0.19, p<0.001)$ across gender and students status. This relationship was significantly stronger among females $(\beta=0.33, p<0.001)$ than among males $(\beta=0.11 \mathrm{p}<0.05)$.
\end{abstract}

Conclusion: The results indicate that strengthening beliefs in the presence of accurate knowledge might successfully promote students' oral health enhancing behaviour.

\section{INTRODUCTION}

In the sub-Saharan African countries, including Tanzania, information on oral health situation is far from complete(1). According to available evidence, the prevalence of tooth decay seem to have remained stable at low levels(2), whereas gingival blceding and calculus are prevalent in the general population, particularly among men(3). Northern Tanzania is facing the problem of high fluoride contents in the drinking water with endemic fluorosis constituting a prominent problem functionally and aesthetically(1). Moreover, a traditional detrimental practice labelled the "Nylon teeth myth" has gained momentum over the last two decades(4).

Currently, in Tanzania there are a few formal mechanisms for educating young people about selfprotection from adverse oral health outcomes $(5,6)$.
Nevertheless, to cope with the scarce number of dental professionals, a strategy involving teachers and mother child health $(\mathrm{MCH})$ nurses in educating primary school children and expecting mothers about oral health has been adopted(7). Oral health education is also provided through a mass media programme, organised by the Ministry of Health in collaboration with the Tanzania Food and Nutrition Centre. Affluent urban people such as university students are by far the most important target group for the mass media oral health education program.

Traditionally, oral health education in Tanzania has been planned and evaluated according to clinical epidemiological data, whereas accurate information on the scope and extent of individual determinants of oral health seems almost neglected (8-10).

Available studies are mainly limited to the 
examination of the oral health related behaviour and knowledge of school children and studies considering the socio-cognitive correlates of oral health behaviours are rare $(11,12)$. Studies conducted among school teachers and $\mathrm{MCH}$ aids have identified gaps in knowledge about oral health as well as a general reluctance to provide dietary counselling as part of school oral health education(13,14). In the general Tanzanian adult population, tooth cleaning has reportedly been more frequent in females than in males, whereas dental attendance and use of tobacco products are most prevailing in men and the affluent urban population(15,16). Young adults attending higher education institutions in Dar es Salaam are exposed to oral health information through mass media and by the dentist. These activities have so far attracted little attention with respect to monitoring and evaluation. The present study aims to assess exposures to oral health information from local sources, levels of risk awareness, oral health beliefs and behaviour as reported by students attending higher education institutions in Dar es Salaam.

\section{MATERIALS AND METHODS}

Sample collection: A two-wave cross-sectional study was conducted during the summer of 1999, involving 1945 year old students enrolled at the University of Dar es Salaam, (UDSM). Constituting a homogeneous socially affluent group of the Tanzanian adult population, university students have, more or less, frequently been exposed to oral health educational programmes and dental services. For this reason and also in order to ensure literacy in English, university students were selected purposely for this study. The UDSM is the largest public recognised university of Tanzania. It has 12 faculties and 10 institutes with a total enrolment of about 5100 students (21.5\% females) (18). Five faculties (Education, Nursing, Medicine, Pharmacy, Dentistry) and three institutes (Allied Health Sciences, Dar es Salaam Institute of Technology and Institute of Business Education) were eligible for study, because UDSM was busy with examinations during the period of the data collection. All students $(n=1920)$ enrolled were invited to participate. A total of 1123 subjects, of which $32 \%$ were females (response rate $58 \%$, mean age 26.4 years, SD 4.2) completed structured questionnaires in English, the medium of instruction in the participating university (Table 1). Confidentiality was ensured and trained Tanzanian research staff supervised the questionnaire survey, administered in ordinary classrooms at the UDSM. Non-response was mainly due to the fact that many students were taking their final examinations and thus were not available on the days the questionnaire was administered. The survey instrument was adapted from that developed by the Tanzanian adult morbidity and mortality project(17), and from survey instruments previously tested in Tanzania and Uganda(14). It was peerreviewed for content validity and revised before being used in the field. A re-test of the whole survey instrument was undertaken among 33 participants after a time interval of 15 days. Informed consent was requested from each participant and ethical clearance was obtained from the research and ethical committee of the Ministry of Health and the University of Dar es Salaam.
Table 1

Absolute ( $n$ ) and relative (\%) distribution of subjects according to type of study subject (students' status), age and place of residence where raised

Demographic

factor Females Males

\begin{tabular}{|c|c|c|c|c|}
\hline & $\mathrm{No}^{*}$ & $\%$ & $\mathrm{~N}$ & $\%$ \\
\hline 1. Medical & 236 & 65 & 399 & 53 \\
\hline Non-medical & 125 & 35 & 360 & 47 \\
\hline 2. Age (years): $19-25$ & 257 & 72 & 336 & 45 \\
\hline$>25$ & 99 & 28 & 414 & 55 \\
\hline 3. Urban & 288 & 81 & 463 & 61 \\
\hline Rural & 69 & 19 & 291 & 39 \\
\hline
\end{tabular}

*The total number in the different categories do not add up to 1123 owing to missing values

Questionnaire: Oral health enhancing behaviour was assessed by asking how often (during the last three months) students had used a plastic toothbrush, fluoridated toothpaste and toothpicks. The response categories for each question ranged from (i) several times a day to(vi) never. For cross tabulation analyses, each item was re-coded into (i) several times a day and (ii) less often. The students were further asked how often they had visited a dentist with responses ranging from (i) twice a year or more to (iv) never. A dummy variable was created yielding the categories (i) at least once a year and (ii) seldom/never. A measure of ever use of tobacco was obtained by asking the students whether they had ever smoked, chewed or sniffed any tobacco products. Responses were scored as (i) no; to (ii) yes. Rather than constructing a simple formative index, the oral health behaviours were subjected to a principal component analysis, PCA, using a valimax orthogonal rotation procedure. Two factors were extracted with eigenvalues greater than 1. The first factor was composed of tooth brushing, use of fluoridated toothpaste and no use of tobacco products, which all loaded meaningfully $(<0.25)$ only on this factor. It explained a total of $32.5 \%$ of the variance. The second factor was composed of the items assessing dental attendance and use of toothpicks and explained a total of $22 \%$ of the variance. The oral health behaviours included in factor 1 and 2 were added into two sum scores, yielding "Individual preventive behaviour" (mean=4.1, sd=1.4, range: $3-12$ ) and "Professional preventive behaviour" (mean $=6.1, \mathrm{sd}=2.2$, range: $2-10$ ), respectively. The higher the scores on these sum-indexes, the less frequent engagement in individual and professional preventive behaviour, respectively.

Risk awareness was assessed using eight statements (e.g. "Use of tobacco products might contribute to the development of oral cancer"). The students rated each statement as (i) correct; and (ii) incorrect. For the multiple regression analyses the statements were combined into a sum index (overall mean $=10.2, s d=1.5$, range $8-16$ ). The lower the score on this sum index the higher the level of knowledge about oral health.

Oral health beliefs were assessed using seven statements concerning the importance of preventive behaviours for the maintenance of good oral health. Responses were given on a scale ranging from (i) "very important" to (v) "very unimportant". For the multiple regression analyses the 
statements were combined into a sum index (overall mean= 10. $1, \mathrm{sd}=3.0$, range 7-35). The lower the score on this sum index the stronger the oral health beliefs.

Exposure to oral health information was assessed by asking the students how much information about the causes of dental fluorosis (pitted coloured and fractured teeth), tooth decay and gum disease they had received from the mass media (magazines, newspapers, radio, television), primary school teachers and dentists. Responses were given on scales ranging from (i) "very much" to (v) "none at all". Three sum indexes were constructed yielding "exposure to information about dental fluorosis" ( mean $=8.8, \mathrm{sd}=2.7$, range: $3-15)$, "exposure to information about tooth decay" (mean= 8.9, sd $=2.8$, range: $3-15$ ) and "exposure to information about gum disease" (mean $=9.8, \mathrm{sd}=2.9$ range: $3-15$ ). The higher the score on each scale the less information received about oral health.

Students provided demographic information including: sex (i) "female" (ii) "male"; place of residence were raised (i) "city/town" (ii) "village/rural"; age at last birthday was re coded into (i) "19-25 years" and (ii) "above 25 years"; and study subject (i) "medical" (ii) "non-medical".

Statistical analysis: Analysis was performed using crosstabulation analysis (Chi square test), independent sample ttest and Pearson's product moment correlation. Reliability test (test-re-test) was conducted using kappa statistics, whereas internal consistency reliability was obtained by use of Cronbach's alpha. Univariate analysis of variance (General linear models, GLM) were conducted to test for gender differences in sum score variables adjusting for age, urbanrural localities and medical-non medical status. Multivariate analyses by use of stepwise linear regression were performed after using non-linear transformation (log-transformation) to re-express the data so that their distributions were more consistent with the parametric - test requirements (18).

\section{RESULTS}

As a general impression, both male and female students seemed to have received more information about dental fluorosis and tooth decay than about gum disease (Table 2). Mass media and school teachers were the most frequent sources of information concerning dental fluorosis and tooth decay. As compared to males, females had received more information about tooth decay from mass media $(2.8$ versus $2.6, p<0.05)$ and the school teacher $(3.0$ versus $2.8, p<0.05)$. The differences observed at the level of gender were generally maintained at the age subgroup level. Moreover, the age related pre-conditions for being exposed to oral health information did not differ between the genders.

The mean distribution for oral health beliefs according to gender and age is illustrated in Table 3. Female students were, more likely than their male counterparts to believe in the importance of limited sugar consumption ( 1.4 versus $1.6, \mathrm{p}<0.001)$, making regular dental visits $(1.2$ versus $1.4, p<0.05)$ and performing daily tooth brushing $(1.2$ versus $1.3, \mathrm{p}<0.05)$. Among males, the 19-25 year olds seemed to be less likely than their older counterparts to hold favourable attitudes with respect to avoiding tobacco products, avoiding consumption of excessive fluoridated water and towards avoiding extraction of "nylon teeth". Among female students the corresponding age differences were not statistically significant.

There was little systematic variation in students risk awareness according to gender and age (not shown in Table). Almost all the female and male students investigated were informed that sugar consumption might cause tooth decay $(96 \%$ versus $90 \%, \mathrm{p}<0.001$ ) and that irregular tooth brushing might lead to gum disease ( $82 \%$ versus $80 \%$, n.s) and tooth decay $(79 \%$ versus $78 \%$, n.s). In contrast, only moderate proportions of female and male students investigated confirmed that exposure to fluoride might cause skeletal fluorosis (45\% versus $48 \%$, ns) and that the nylon teeth myth is a health detrimental practice $(64 \%$ versus $67 \%$, n.s).

Table 2

Mean scores and standard deviation (sd) for responding student's exposure to local source of oral health information by gender and age

\begin{tabular}{|c|c|c|c|c|c|c|}
\hline & \multicolumn{3}{|c|}{ Females } & \multicolumn{3}{|c|}{ Males } \\
\hline & $\begin{array}{c}\text { All } \\
(n=356)\end{array}$ & $\begin{array}{c}19-25 \mathrm{yrs} \\
(\mathrm{n}=257)\end{array}$ & $\begin{array}{c}>25 \text { yrs } \\
(n=99)\end{array}$ & $\begin{array}{c}\text { All } \\
(n=750)\end{array}$ & $\begin{array}{c}19-25 \text { yrs } \\
(n=336)\end{array}$ & $\begin{array}{l}>25 \text { yrs } \\
(n=414)\end{array}$ \\
\hline \multicolumn{7}{|c|}{ Heard about fluorosis: } \\
\hline Media & $2.8(1.1)$ & $2.8(1.1)$ & $2.7(1.1)$ & $2.8(1.1)$ & $2.9(1.0)$ & $2.8(1.1)$ \\
\hline Teacher & $2.8(1.2)$ & $2.8(1.2)$ & $2.6(1.1)$ & $2.9(1.1)$ & $2.9(1.1)$ & $2.8(1.2)$ \\
\hline Dentist & $3.1(1.4)$ & $3.0(1.4)$ & $3.2(1.3)$ & $3.2(1.4)$ & $3.1(1.3)$ & $3.3(1.4)$ \\
\hline \multicolumn{7}{|c|}{ Heard about tooth decay } \\
\hline Media & $2.6(1.1)$ & $2.7(1.1)$ & $2.6(1.1)$ & $2.8(1.1)^{*}$ & $2.8(1.0)$ & $2.8(1.1)$ \\
\hline Teacher & $2.8(1.1)$ & $2.8(1.2)$ & $3.0(1.1)$ & $3.0(1.2)^{*}$ & $3.0(1.0)$ & $2.9(1.1)$ \\
\hline Dentist & $3.0(1.7)$ & $3.0(1.9)$ & $3.1(1.4)$ & $3.2(1.5)$ & $3.2(1.7)$ & $3.2(1.4)$ \\
\hline \multicolumn{7}{|c|}{ Heard about gum disease } \\
\hline Media & $3.2(1.2)$ & $3.3(1.2)$ & $3.2(1.2)$ & $3.3(1.1)$ & $3.3(1.1)$ & $3.3(1.2)$ \\
\hline Teacher & $3.2(1.2)$ & $3.3(1.2)$ & $3.3(1.2)$ & $3.3(1.1)$ & $3.4(1.1)$ & $3.3(1.2)$ \\
\hline Dentist & $3.1(1.3)$ & $3.0(1.3)$ & $3.3(1.4)$ & $3.3(1.4)^{*}$ & $3.2(1.4)$ & $3.4(1.4)$ \\
\hline
\end{tabular}


Table 3

Mean scores and standard deviation (sd) for respondents' oral health beliefs according to gender and age

\begin{tabular}{lcccccc}
\hline & \multicolumn{3}{c}{ Females } & \multicolumn{3}{c}{ Males } \\
\cline { 2 - 7 } Belief statement & All & $19-25$ yrs & $>25$ yrs & All & $19-25$ yrs & $>25$ yrs \\
\hline Limited sugar & $1.4(0.7)$ & $1.5(0.7)$ & $1.3(0.5)$ & $1.6(0.8)^{* *}$ & $1.6(0.9)$ & $1.6(0.7)$ \\
Regular dental visits & $1.2(0.6)$ & $1.3(0.6)$ & $1.2(0.6)$ & $1.4(0.6)^{*}$ & $1.4(0.6)$ & $1.4(0.6)$ \\
F-toothpaste & $1.2(0.5)$ & $1.1(0.5)$ & $1.2(0.4)$ & $1.2(0.5)$ & $1.2(0.6)$ & $1.1(0.6)^{*}$ \\
Avoid tobacco & $1.2(0.8)$ & $1.3(0.8)$ & $1.3(1.0)$ & $1.3(0.9)$ & $1.4(1.0)$ & $1.2(0.8)^{*}$ \\
Exposure to fluoride & $1.6(1.0)$ & $1.6(1.0)$ & $1.6(1.1)$ & $1.6(1.0)$ & $1.7(1.1)$ & $1.5(0.8)^{*}$ \\
Tooth brushing & $1.2(0.5)$ & $1.2(0.5)$ & $1.2(0.5)$ & $1.3(0.6)^{*}$ & $1.3(0.5)$ & $1.3(0.6)$ \\
"Nylon teeth" & $1.8(1.3)$ & $1.9(1.3)$ & $1.7(1.2)$ & $1.8(1.2)$ & $2.1(1.2)$ & $1.7(1.1)^{* *}$ \\
\hline
\end{tabular}

$* * p<0.001, * p<0.05$

As shown in Table 4, moderate proportions of female and male students reported regular dental attendance, frequent daily tooth brushing, use of fluoridated tooth paste and tooth picks. Females were consistently more likely than males to confirm engagement in oral health enhancing behaviours. The differences observed at an overall gender level were maintained at the age subgroup level. However, among males but not among females oral health enhancing behaviour differed significantly according to age.

Sum scores of oral health knowledge, oral health beliefs, information about fluoride, information about gum disease, information about tooth decay, individual preventive behaviour and professional preventive behaviour were computed. The raw mean values were adjusted for differences in age, urban-rural gradient and medical - non medical status, using analysis of variance (not shown in Table). The results revealed that, as compared to males, females had been exposed to more information about tooth decay (8.6 versus $9.1, \mathrm{~F}=6.3$, $\mathrm{P}<0.05)$, had stronger beliefs $(9.4$ versus $10.2, \mathrm{~F}=12.7$, $\mathrm{p}<0.001)$ and engaged more frequently in personal $(3.9$ versus $4.3, F=116.1, \mathrm{p}<0.001$ ) and professional (5.7 versus $6.4, F=21.5, p<0.001$ ) preventive oral health behaviours. The results revealed further that medical students engaged more frequently than their non medical counterparts in personal preventive behaviour (3.9 versus $4.9, F=11.9, p<0.05$ ), whereas students raised in urban areas engaged more frequently than their rural counterparts in professional preventive behaviour $(5.8$ versus $6.3, \mathrm{~F}=13.2, \mathrm{p}<0.001$ ).

In a stepwise multiple regression analysis predicting individual preventive behaviour (Table 5), demographic variables (gender, study subject) explained $3.5 \%$ point ( $R$ square change $=0.035, F$ change $=17.3(2,958)$, $\mathrm{p}<0.001$ ). Entering exposure to oral health information, risk awareness and beliefs, significantly increased the explained variance by $5.9 \%$ points ( $R$ square change= $0.059, F$ change $=12.4(5.953), p<0.001)$. Of the individual variables, information about tooth decay $(\beta=$ $0.23, p<0.001)$ and oral beliefs $(\beta=0.19, p<0.001)$ turned out to be the most important predictors of personal preventive behaviour (Table 5). In a separate multiple linear regression model, one-way interaction terms (gender $\mathrm{x}$ beliefs, gender $\mathrm{x}$ exposure to information about tooth decay) were added after controlling for the main variables in the model. Only the interaction term gender $x$ oral health beliefs made a significant contribution to the explained variance; $R$ square change $=0.008, F$ change $=8.617(1,952), \mathrm{p}<0.005$. Separate regression analyses for males and females revealed that oral health beliefs remained as a significant predictor across gender, but were more strongly associated with personal preventive behaviour in females $(\beta=0.33$, $\mathrm{p}<0.001)$ than in males $(\beta=0.11, \mathrm{p}<0.05)$.

Table 4

Percentage distribution (n) of respondents' oral health enhancing behaviours by gender and age

\begin{tabular}{lcccccc}
\hline & \multicolumn{3}{c}{ Females } & \multicolumn{3}{c}{ Males } \\
\cline { 2 - 7 } & All & $19-25$ yrs & $>25$ yrs & All & $19-25$ yrs & $>25$ yrs \\
\hline Tooth brushing & $70(252)$ & $70(180)$ & $69(69)$ & $56(425)^{* *}$ & $63(212)$ & $50(208)^{* *}$ \\
Fluoridated toothpaste & $66(237)$ & $67(171)$ & $62(62)$ & $52(390)^{* *}$ & $60(202)$ & $44 .(182)^{* *}$ \\
Tooth picks & $44(157)$ & $43(109)$ & $49(48)$ & $35(265)^{*}$ & $36(122)$ & $34(140)$ \\
Dental attendance & $43(154)$ & $45(115)$ & $37(37)$ & $23(174)^{* *}$ & $23(78)$ & $22(94)$ \\
No tobacco use & $99(341)$ & $99(240)$ & $100(95)$ & $89(654)^{* *}$ & $88(279)$ & $90(365)$ \\
\hline
\end{tabular}

$* \mathrm{p}<0.001, * \mathrm{p}>0.05$ 


\section{Table 5}

Personal preventive behaviour regressed on exposure to oral health information, risk awareness and oral health beliefs after controlling for socio-demographic factors

\begin{tabular}{lccc}
\hline Predictor & $B$ & $\beta$ & p-value \\
\hline Information about fluorosis & 0.03 & 0.07 & 0.213 \\
Information about tooth decay & 0.12 & 0.23 & 0.000 \\
Information about gum disease & -0.03 & 0.06 & 0.227 \\
Knowledge & 0.03 & 0.03 & 0.356 \\
Beliefs & 0.09 & 0.19 & 0.000 \\
\hline
\end{tabular}

\section{DISCUSSION}

The participants of this study were students raised in different regions of Tanzania attending higher education institutions at the UDSM in Dar es Salaam. Although the response rate obtained was less than ideal, it has probably not entailed non-response error that compromised the results presented(19). According to the University of Dar es Salaam Prospectus (1998/ 1999), the gender distribution of the participants coincides with figures pertaining to the eligible study population, indicating that the non-response rates among males and females were broadly similar.

The majority of the participants had been exposed to information about dental fluorosis and tooth decay through mass media and through communication with teachers in primary school. Although oral hygiene measures have been emphasised in the schools' health curriculum, information about gum disease ranked relatively low in Table 2 . In contrast to western studies, indicating that dentists are the main source of oral health information(20), Tanzanian dental health workers seem to be under-utilised. Rather, the mass media and teachers are primary sources of oral health education among students in Tanzania. The findings are encouraging in terms of continuing the promotion of oral health education through radio, newspapers, television and the primary school curriculum. Female students confirmed to have heard more about tooth decay from the mass media and the teachers and scored higher on the information about tooth decay scale than did their male counterparts. Apparently, the evidence that women are less likely than men to be informed from mass media due to the Tanzanian socio-cultural context(21) was not confirmed by this study. The finding that dental health workers were infrequent sources of oral health information relative to mass media and teachers might be explained by the fact that the pupils have less contact with the former than the latter source of information. Alternatively the dentists do not take advantage of young people's consultation as an opportunity to provide not only treatment but also oral health related counselling.

Almost all students were informed that frequent sugar consumption increases the risk of getting tooth decay. Because students admitted to have received as much information about excessive exposure to fluoride, they should expectedly be knowledgeable about endemic fluorosis as well. However, gaps were observed on this issue, most apparently with respect to the link between fluoride and disease in the skeleton. Moreover, a relatively high proportion of students was misinformed about the detrimental practice of removing "nylon teeth". A probable explanation for their misconceptions might be that those issues are less directly related to their own lives. Thus, it is feasibly that they have focussed more on the information they need to protect their own oral health. On the other hand, the large majority of students had strong beliefs on the importance of preventive behaviours for maintenance of good oral health, though females appeared to be more convinced than their male counterparts.

Compared to men, women are generally less likely to smoke and engage more frequently in preventive oral behaviours. This gender gradient has been repeatedly observed in occidental studies and has been interpreted as being consistent with the traditional norms for sexrole appropriate behaviour(22). The high prevalence of daily tooth brushing reported by the students is less surprising in light of previous findings among school children(11). Finally, the observed rates of tobacco use corroborate those previously reported among young people in Tanzania(15), but seem to be below the figures reported from other sub-Saharan countries(23).

Of greater importance, is the fact that exposure to information about oral health, knowledge, belief and personal preventive behaviour were related as might be expected from a theoretical point of view, indicating that the corresponding scales all measure different constructs(24). The Health Belief Model maintains that habits are a function of perceived vulnerability to a disorder and the belief that a particular preventive measure will be sufficient to overcome this vulnerability. Since construct validity is directly concerned with theoretical relationships, the observed associations, harmonising with theoretical propositions add to the validity of the results.

In interpreting the results of this study, some limitations need to be considered. First, only young adults attending higher learning institutions located in an urban area were studied. Due to the rich geographical and socio-cultural diversity within Tanzania it is not possible to generalise from the studied population to any larger population of young adults inside or outside Dar es Salaam. This should, however, not belittle the findings presented here, provided it is borne in mind that they are not representative of the Tanzanian adult population but are illustrative of a selected but important group. Secondly, the study design has a potential for some form of information bias in terms of social desirability and or recall biases. However, we believe that the use of anonymous self-administered questionnaires assuring confidentiality of the information 
collected may have made it easier for the participants to respond honestly.

In summary, the close link observed between behaviour and beliefs emphasises the importance of cognitive factors(10). Although, this relationship was stronger among females than males, suggesting that females are more capable to take advantages of their beliefs, it appeared consistently across gender and students' subject status. Evidence that exposure to health information is especially beneficial for females have been reported elsewhere, illustrating the importance of taking gender into account in any evaluation(25). Risk awareness seems to play a less direct role for individual preventive behaviour, which is in agreement with previous findings among young adults in East Africa and western societies(14,25). The results appear to imply that strengthening oral health beliefs in the presence of correct knowledge might successfully promote individual preventive behaviours among Tanzanian university students. It seems important, however, to explore why male students receive less oral health information than their female counterparts and what are the barriers hampering them from being more engaged in oral health enhancing behaviour. The results indicate that a variety of arenas including mass media, schools and oral health care facilities can be used to provide oral health information and education to Tanzanian students. Finally, constructs such as oral health beliefs and knowledge needs further development in additional studies.

\section{ACKNOWLEDGEMENTS}

The Centre for International Health has provided permission to publish the present data. The authors would like to thank the participants involved and the guidance of Dr. Lameek Mabelya and Dr. Wicliff Lugoe on the cultural aspects of this study. The financial support from the University of Bergen and the NUFU grants $61 / 96$ is gratefully acknowledged.

\section{REFERENCES}

I. Hobdell, M.H., Myburgh, N.G., Lallo, R., Chikte, U.M.E. and Owen. C.P. Oral diseases in Africa: a challenge to change oral health priorities. Oral Diseases 1997; 3: 216222.

2. Mosha, H.J., Ngilisho, L., Nkwera, H., Scheitz, R. and Poulsen, S. Oral health status and treatment needs in different age groups in two regions of Tanzania. Community Dent Oral Epidemiol 1993; 22: 307-310.

3. Murrighamba, E.G.S., Markkanen, H.A. and Honkala, E. Periodontal status and treatment needs in rural areas of Ukonga Tanzania. Int Dent $J$ 1996; 46: 156-160.

4. Hiza, L.F.R. and Kikwilu, E.N. Missing primary teeth due to tooth-bud extraction in a remote village in Tanzania. Int Paed Dent 1992; 2: 31-34.

5. World Health Organisation. Prevention methods and program for oral diseases.Technical Report series 713. Geneva: WHO, 1984

6. Tapshoba, H. and Deschamps, LP. Promotion of orodental health in Africa. Promotion et Education 1997; 4:26-28.

7. Ministry of Health. The National Plan for Oral Health for 1988-2000. The United Republic of Tanzania, 1994.

8. Van Palenstein Helderman, H.W., Murick, L.. Mushendwa, S., Van't Hof, M.A. and Mrema, F. Effect evaluation of an oral health education programme in primary schools in Tanzania. Community Dent. Oral Epidemiol. 1997; 25: 296300.

9. Watt, R., Fuller, S., Harnett, R., Treasure, E., StillmanLowe, C. Oral health promotion evaluation time for development. Community Dent. Oral Epidemiol. 2001; 29: 161-166.

10. Conner, M., Norman, P. The role of social cognitions in health behaviour. In: Conner $M$, Norman $P$, (eds). Buckingham: Open University Press, pp 1-23, 1995.

11. Normark, S., Mosha, H.J. Knowledge, practices and dental health among Tanzanian children. African Dent. J. 1989; 3: 24-33,

12. Nyandindi, U., Palin-Palokas, T., Millen, A., Robinson, V., Kornbe, N. Oral health knowledge, attitudes, behaviour and skills of children entering school in urban and rural areas of Tanzania. Publ Health 1994; 108: 35-40.

13. Nyandindi, U., Palin-Palokas, T, Millen, A., Robinson, V., Kornbe. N., Mwakasagule, S. Participation, willingness and abilities of school teachers in oral health education in Tanzania. Community Dent. Health. 1994; 11: 101. 104.

14. Astrom, A.N. Jackson, W., Mwangosi I.E.A.T. Knowledge, beliefs and behaviour related to oral health among Tanzanian and Ugandan teacher trainees. Acta. Odontol. Scand. 2000: 58: $11-18$.

15. Kitange, H.M., Swai, A.B., Masuki, G., Kilima, PM, Alberti, K.G. and MacLarty, D.G. Coronary heart disease factors in sub-Saharan Africa: studies in Tanzanian adolescents. J. Epidem. and Community Health. 1993; 47: 303-307.

16. Mosha, H.J. and Scheutz, F. Perceived need and use of oral health advises among adolescents and adults in Tanzania. Community Dent. Oral Epidemiol. 1993; 21: 129-132.

17. Weinsten, K.1., Ngallabra, S., Cross, A.R. and Mbuni, F.M. Tanzania knowledge, attitudes and practices survey 1994. Bureau of Statistics, Planning Commission, Dar es Salaam, 1995.

18. Cohen, M.E. Analysis of ordinal data: Evaluation of conflicting recommendations. J. Dent. Res. 2001; 80: 309313.

19. Locker, D. Response and non-response biases in oral health surveys. J. Public Health Dent. 2000: 60: 72-81.

20. O'Neill, H.W Opinion study comparing attitudes about dental health. J American Dent. Assoc. 1984: 109: 910-915.

21. Kapiga, S.H., Nachtigal, G. and Hunter, D.J. Knowledge of AIDS among secondary school children in Bagamoyo and Dar es Salaam, Tanzania. AIDS. 1991; 5: 325-328.

22. Waldron, I. Gender and health related behaviour. In: Gochman DS, editor. Health behaviour: emerging perspectives. New York: Plenum Press, pp 193-208, 1988.

23. Adelekan, M.L., Ndom, RJ. Trends in prevalence and patterns of substance use among secondary school pupils in Ilorin, Nigeria. West African J. Medicine. 1997; 16: 157164.

24. Gabhann, S.N., Kelleher, C.C. School health education and gender: an interactive effect? Health Educ. Res. 2000; 15: 591-602.

25. Freeman, R., Heimonen, H., Speedy, P., Tuutti, H. Determinants of cariogenic snacking in adolescents in Bekfast and Heslinki. Eur. J. Oral Sci. 2000; 108:504-510. 